\title{
Kaudal Blok Uygulanan Pediatrik Hastalarda Ultrason ile Konvansiyonel Kör Tekniğin Karşılaştırılması
}

\author{
Sami Eksert ${ }^{1}$, Ender Sir $^{2}$ \\ ${ }^{1}$ Gülhane Eğitim Araştırma Hastanesi, Anestezi ve Reanimasyon Kliniği, Ankara, Türkiye \\ ${ }^{2}$ Gülhane Eğitim Araştırma Hastanesi, Algoloji Kliniği, Ankara, Türkiye \\ exert79@yahoo.com, endersir@gmail.com, \\ Orcid: 0000-0001-5566-286X \\ Orcid: 0000-0003-2628-135X \\ *Sorumlu Yazar / Corresponding Author: Sami EKSERT \\ Gönderim Tarihi / Received:18.02.2019 \\ Kabul Tarihi / Accepted: 19.06.2019 \\ DOI: $10.34087 /$ cbusbed.528317
}

\begin{abstract}
Öz
Giriş: Son yıllarda, rejyonel anestezi uygulamalarında, hem güvenilirlik hem de başarı oranını artırması nedeniyle ultrason kullanımında artış söz konusudur. Pediatrik hastalarda, konvansiyonel kör teknikle kaudal blok uygulamalarında, sakral kanal içerisinde iğne ucunun yeri görüntülenemediği için cilt altı veya intraosseöz gibi yanlış enjeksiyon yapılma riski mevcuttur. Bu çalışmada amacımız pediatrik vakalarda ultrason veya kör teknikle uygulanan kaudal bloğu, etkinlik ve komplikasyonlar açısından karşılaştırmaktır.

Yöntem: Kasım 2016 ve Şubat 2018 arasında, genel anestezi altında, tek taraflı kasık fitığı veya sünnet cerrahisi geçiren, intraoperatif kaudal blok uygulanmış olan pediatrik yaş grubundaki hastaların dosyaları ve takip formları incelendi. Ultrason rehberliğinde (GrupU, n:18) ve konvansiyonel kör teknikle (GrupK, n: 20) kaudal blok yapılan 2-10 yaş aralığında toplamda 38 hasta çalışmaya dahil edildi. Hastaların demografik verileri, işlem sırasında çoklu enjeksiyon girişimi olup olmadığ , komplikasyonlar, postoperatif ilk 12 saate analjezik kullanımı hasta takip formlarına kaydedildi.
\end{abstract}

Bulgular: İşlem sırasında GrupU ve GrupK'da, ilk denemede başarılı enjeksiyon \% 94.4 (17/18) ile \% 65.0 (13/20), ( $p: 0.04)$ değerindeydi. Cilt altı enjeksiyon \% $5.6(1 / 18)$ ile \% $25.0(5 / 20),(p: 0.18)$, kan aspirasyonu \%5.6 (1/18) ile $\% 20(4 / 20),(p: 0.34)$, BOS aspirasyonu \%0 (0/18) ile \%10 (2/20), (p:0,48) olarak tespit edildi. Sistemik toksisite her iki grupta da görülmedi. Postoperatif ilk 12 saatte analjezik kullanımı Grup U'da \% 11,1 (2/18) iken Grup K'da \%20 (4/20) (p:0.45) idi.

Sonuç: Pediatrik inguinal herni ve sünnet operasyonlarında, ultrason rehberliğinde kaudal blok uygulanan hastalarda, konvansiyonel kör tekniğe göre postoperatif ilk 12 saatte analjezik kullanımı ve komplikasyon oranı benzer iken ilk seferde başarılı enjeksiyon oranı daha yüksek gözlendi.

Anahtar Kelimeler: Ultrason, Kaudal, Epidural.

\section{Abstract}

Objective: In recent years, the reliability and success of ultrasound-guided regional block applications in anesthesia practice has been demonstrated. There is a risk of improper injection such as subcutaneous or intraosseous in pediatric patients due to the fact that the needle tip and the spread of local anesthetic cannot be visualised in the sacral canal during the conventional approach. In this study, our aim was to compare conventional and ultrasound guided caudal block in terms of efficacy and complications in pediatric cases.

Methods: The files and follow-up forms of pediatric patients who underwent unilateral inguinal hernia or circumcision surgery under general anesthesia caudal block between November 2016 and February 2018, were reviewed. A total of 38 patients, 2-10 years old, who underwent caudal block with ultrasound guidance (Group U, $\mathrm{n}: 18$ ) and conventional blind technique (Group B, n:20) were included in the study. The demographic data of the patients, the presence of multiple injections during the procedure, complications, and the use of analgesics in the first 12 hours were recorded in follow-up forms.

Results: In Group U and Group B, respectively; successful injection at the first attempt was 94.4\% (17/18) to 65\% (13/20),(p:0.04). Subcutaneous injection was 5.6\% (1/18) to 25\% (5/20),(p:0.18), aspiration of blood was 5.6\% $(1 / 18)$ to $20 \%(4 / 20),(p: 0.34)$, and CSF aspiration was $0 \%(0 / 18)$ to $10 \%(2 / 20),(p: 0,48)$. Systemic toxicity was not 
observed in both groups. Postoperative analgesic use in the first 12 hours was $11.1 \%(2 / 18)$ in Group U and 20\% (4/20) in Group B (p:0.45).

Conclusion: In pediatric inguinal hernia and circumcision operations, analgesic use in the first 12 hours and complication rates were similar while successful injection in the first time was higher in patients who underwent caudal block with ultrasound guidance when compared to conventional blind technique.

Key words: Ultrasound, Caudal, Epidural.

\section{Giris}

Pediatrik hasta gruplarında, kaudal blok intraoperatif ve postoperatif ağrı kontrolü amacıyla kullanılan etkin bir analjezi yöntemidir [1]. T10- S5 dermatom sahasını etkileyen inguinal herni, sünnet ve appendektomi vakalarında uygulanabilir [2]. Konvansiyonel kör teknikte, iki sakral kornu palpe edildikten sonra, iğne ile kornuların arasından sakral hiatusa 45 derece açı ile girilir. İğne sakruma çarptıktan sonra birkaç milimetre geri çekilip açı azaltılır ve epidural alana 'ani geçme hissi' alınana kadar sakral kanalda iğne ilerletilir [3]. Kaudal enjeksiyon sırasında intraosseöz, cilt altı, dural, vasküler enjeksiyon ve sistemik lokal anestezi toksisitesi oluşabilecek komplikasyonlardandır [4].

Son yıllarda rejyonel anestezi uygulamalarında ultrasonun kullanımı yaygınlaşmıştır. Ultrason eşliğinde kaudal blok uygulaması ilk olarak Klocke ve ark [5] tarafından uygulanmıştır. Ultrason rehberliğinde kaudal blok uygulamasında, sakrum, sakral kornular, sakrokoksigeal ligament ve sakral hiatus kolaylıkla ayırt edilebilir. Ayrıca sakral hiatusun ve işlem bölgesinin anatomik varyasyonları da net bir şekilde gözlenebilir [6]. Ultrason rehberliğinde ilerletilen iğnenin istenilen yönde ilerlemesi, lokal anestezik enjeksiyonu ile sakral kanalda genişleme ve renkli Doppler ile sakral kanal içindeki enjeksiyon esnasında türbülans gözlenmesi, enjeksiyonun doğru yapıldığını gösterir. Böylece eş zamanlı görüntüleme ile komplikasyonlarda azalma ve işlem başarısında artış sağlanabilir [7,8].

Bu çalışmada amacımız, genel anestezi altında inguinal herni ve sünnet operasyonu geçiren çocuk hastalarda, konvansiyonel kör teknik ve ultrason eşliğinde uygulanan kaudal bloğun başarı ve komplikasyon oranları ile postoperatif anajezik kullanımı arasındaki farkı araştırmaktı.

\section{Gereç ve Yöntem}

Etik onam, yerel etik kuruldan, $(2018 / 6,18 / 121)$ say1 numarası ile alındı. Kasım 2016-Şubat 2018 tarihleri arasında Gülhane Eğitim Araştırma Hastanesi Anestezi Kliniğinde genel anestezi altında, 15 tek taraflı kasık fitığ 1 ve 23 sünnet uygulanan toplam 38 hastanın dosya ve anestezi takip formları retrospektif olarak tarand1. Ultrason eşliğinde (Grup $\mathrm{U}, \mathrm{n}: 18$ ) ve kör teknikle kaudal blok (Grup K, n: 20) yapılan 2-10 yaş aralığında, Amerikan Anestezistler Derneği (ASA) fiziksel statüsü I-II olan toplam 38 hasta çalışmaya dâhil edildi. ASA III-IV, bilateral inguinal herni operasyonu olan veya kaudal bölgede anomalisi olan hastalar çalışma dışı bırakıldı. Her iki teknik de kör ve ultrason eşliğinde kaudal enjeksiyon tecrübesi yüksek tek bir uygulayıcı tarafindan uygulandi.

Ameliyathaneye alınan hastalara rutin olarak elektrokardiyogram, non-invaziv kan basincı, nabız, periferik oksijen saturasyonu monitorizasyon uygulandı. Yüz maskesi Mac: \%8 sevofluran indüksiyonu sonrası üst ekstremiteden 22 ya da 24 GA iğne ile periferik damar yolu açıldı. İndüksiyon amacıyla $1 \mathrm{mg} / \mathrm{kg}$ propofol ve $1 \mu \mathrm{g} / \mathrm{kg}$ fentanil uygulandıktan sonra uygun laringeal maske yerleștirildi. İdame olarak \%50 oksijen, \%50 hava ve Mac:2 sevofluran karışımı ile mekanik ventilasyon uygulandı. Cerrahi işlem öncesi hasta sol yan yatırıldı. Steril şartlar altında tüm hastalara klorheksidin ile cilt asepsisi uygulandı.

Grup U'da, yüksek frekans lineer prob (HFL 50xp, 15-6 $\mathrm{MHz}$, Edge, Sonosite, Bothell, WA, USA) kullanıldı. Ultrason probu orta hatta iki kornu üzerine önce transvers sonra 90 derece çevrilip longitudinal olarak yerleştirilerek sakral konular, sakrokoksigeal ligament ve sakral kemik incelendi (Resim 1). Kaudal yapılarda anomali tespit edilen hastalara kaudal blok uygulanmadı. 22-G, $50 \mathrm{~mm}$ ekojenik nörostimülatör iğnesi (Echoplex, Vygon, Ecouen, France), longitudinal pozisyonda uzun aksta (in-plane), sakrokoksigeal membran geçilerek sakral kanala ilerletildi (Resim 2). Negatif aspirasyon ile kan ve BOS gelmediği kontrol edildikten sonra, $\% 0.25,0.5 \mathrm{ml} / \mathrm{kg}$ dozunda bupivakain uygulandı. Lokal anestezik solüsyonunun enjeksiyonu sırasında kaudal epidural aralıkta genişleme yada doppler ile türbülans akım gözlendi. Cilt altı şişlik görüldüğünde enjeksiyon sonlandırıldı ve ultrason eşliğinde iğne yeniden yönlendirildi.

Resim 1. Kaudal alanın transvers düzlemde ultrasonografik görünümü.

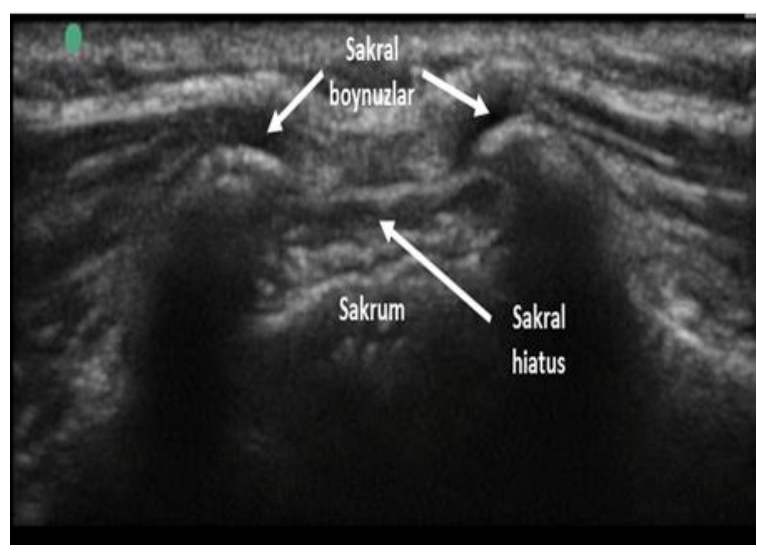

Grup K'de, sakral kornular palpe edilerek, nörostimülatör iğnesi 45 derece açı ile ilerletildi. İğne sakruma çarptıktan sonra birkaç milimetre geri çekilerek, açı azaltıldı ve sakral kanalda epidural alana 
ulaşıldı. Negatif aspirasyon ile kan ve BOS gelmediğ kontrol edildikten sonra, ayn dozda, \% 0,25, 0,5 ml/kg dozunda bupivakain uyguland1.

Ultrason ve kör teknikle uygulanan tüm kaudal enjeksiyonlar tek uygulayıcı tarafindan uygulandı. Her iki grupta yapılan enjeksiyon deneme sayısı, cilt altı enjeksiyon ve aspirasyon ile kan veya BOS gelmesi gibi komplikasyonlar kaydedildi. Post-operatif 12 saatte, 10 $\mathrm{mg} / \mathrm{kg}$ parasetamol kurtarıcı analjezik olarak kullanıld ve hasta takip formalarına kaydedildi. Ultrason ve kör teknikle uygulanan tüm kaudal blok işlemleri bir uygulayıcı anestezist tarafından gerçekleştirildi

Resim 2. Kaudal alanın longitudinal görünümü ve iğnenin yerleșimi.

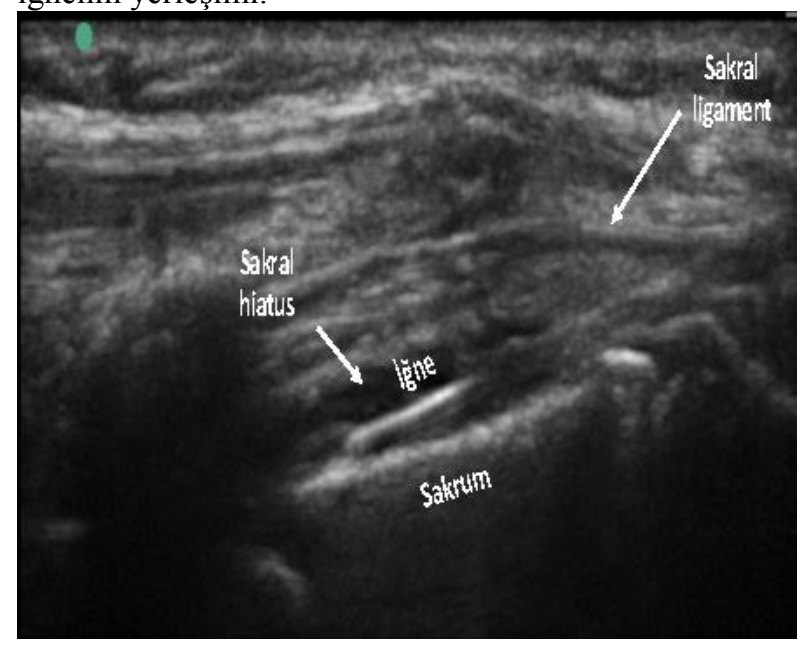

\section{İstatistiksel Analiz}

Veriler bilgisayar ortamına aktarıldıktan sonra analizleri SPSS 21.0 paket programıla yapıldı. Tanımlayıcı istatistikler sayı, yüzde, ortalama ve standart sapma olarak verildi. Kesikli veriler Fisher'in Kesin Testi ile normal dağılıma uymayan ikili gruplardaki sürekli veriler Mann Whitney $U$ testi ile karşılaştırıldı. İstatistiksel anlamlılık değeri olarak $\mathrm{p}<0,05$ kabul edildi.

\section{Bulgular}

Grup U'da 18 Grup K'da ise 20 hasta olmak üzere toplam 38 hasta bu çalışmaya dahil edildi. Grup U ve grup K'nın demografik verileri Tablo 1'de verilmiştir.

Tablo 1. Demografik veriler

\begin{tabular}{|c|c|c|c|}
\hline & Grup U (n: 18) & Grup K (n: 20) & $\mathrm{p}$ \\
\hline Cinsiyet (E/K) & $14 / 4$ & $14 / 6$ & $0.71^{* *}$ \\
\hline ASA (I/II) & $16 / 2$ & $17 / 3$ & $0.94^{* *}$ \\
\hline Fitık/sünnet & $7 / 11$ & $8 / 12$ & $0.94 * *$ \\
\hline Yaş (y1l) * & $4.66 \pm 1.81$ & $4.65 \pm 1.75$ & $0.94 * * *$ \\
\hline Kilo (kg) * & $20.22 \pm 7.15$ & $21.2 \pm 9.97$ & $0.88^{* * *}$ \\
\hline Boy (cm) * & $101.83 \pm 10.91$ & $108.1 \pm 15.95$ & $0.25 * * *$ \\
\hline
\end{tabular}

Gruplara göre enjeksiyonla ilk denemede başarılı olanlarla başarılı olmayanlar arasında istatistiksel olarak anlamlı farklılık bulunmuşken $(\mathrm{p}<0,05)$, cilt altı enjeksiyon yapilanlarla yapılmayanlar, kan ve BOS aspirasyonu olanlarla olmayanlar ve postoperatif ilk 12 saatte analjezik kullananlarla kullanılmayanlar arasında istatistiksel olarak anlamlı bir fark saptanmamıştır ( $>0,05)$ (Tablo 2). Sistemik toksisite her iki grupta da tespit edilmemiștir.

Tablo 2. Kaudal blok verileri

\begin{tabular}{|c|c|c|c|c|}
\hline & & $\begin{array}{c}\text { grup U } \\
\mathrm{n}: 18(\%)\end{array}$ & $\begin{array}{c}\text { grup } \mathrm{K} \\
\mathrm{n}: 20(\%)\end{array}$ & $\mathrm{p}^{*}$ \\
\hline \multirow{2}{*}{ Enjeksiyon } & İlk denemede başarılı & $17(94.4)$ & $13(65.0)$ & \multirow{2}{*}{0.04} \\
\hline & Birden fazla deneme & $1(5.6)$ & $7(35)$ & \\
\hline \multirow{2}{*}{ Cilt altı enjeksiyon } & yok & $17(94.4)$ & $15(75)$ & \multirow{2}{*}{0.18} \\
\hline & var & $1(5.6)$ & $5(25)$ & \\
\hline \multirow{2}{*}{ Kan aspirasyonu } & yok & $17(94.4)$ & $16(80)$ & \multirow{2}{*}{0.34} \\
\hline & var & $1(5.6)$ & $4(20)$ & \\
\hline \multirow{2}{*}{ BOS aspirasyonu } & yok & $18(100)$ & $18(90)$ & \multirow{2}{*}{0.48} \\
\hline & var & 0 & $2(10)$ & \\
\hline Postoperatif ilk 12 & yok & $16(88.9)$ & $16(80)$ & \multirow[b]{2}{*}{0.45} \\
\hline $\begin{array}{l}\text { saatte analjezik } \\
\text { kullanımı }\end{array}$ & var & $2(11.1)$ & $4(20)$ & \\
\hline
\end{tabular}

(*Fisher's Exact Test)

\section{Tartışma}

Son zamanlarda, popülaritesi artan ultrason kullanımı ile konvansiyonel kör teknik ile kaudal blok uygulamasını karşılaştırdığımız çalışmamızda, cilt altı enjeksiyon, kan ve BOS aspirasyonu gibi komplikasyonlar ile postoperatif ilk 12 saatte analjezik kullanımı açısından gruplar arasında anlamlı fark gözlenmedi. Ancak, ilk denemede başarılı enjeksiyon oranı, ultrason eşliğinde yapılan bloklarda anlamlı şekilde yüksek bulundu.

Pediatrik yaş grubunda, ultrason ve konvansiyonel kaudal bloğun karşılaştırıldığı çalışmalarda; ultrasonun, kaudal blok başarı oranını artırmadığı fakat komplikasyon oranını azalttığı gösterilmiştir $[9,10]$. Yetişkin hastaları da içine alan kaudal blok anatomisi ve teknikleri içeren bir derlemede ise ultrason ve 
floroskopinin konvansiyonel kör tekniğe göre başarı oranını artırdığı ifade edilmektedir [6]. Pediatrik yaş grubunda sakral kornuların kolay palpe edilebilmesinin, bu yaş grubunda kör tekniğin başarı oranının yüksek olmasında etkili olduğunu değerlendiriyoruz. Yapılan bir çalışmada yetişkinlerin \%21'inde sakral kornuların palpe edilemediği tespit edilirken, diğer bir çalışmada ise pediatrik yaş grubunda bu oranın \% 12 olduğu belirtilmektedir [11,12].

Kaudal blokta, enjeksiyon yerini doğrulamak amaciyla değişik yöntemler uygulanabilmektedir. Anatomik işaret noktaları kullanılarak uygulanan konvansiyonel kör teknikte, sakrokoksigeal ligamentten 'ani geçme hissi' iğnenin kaudal epidural aralığa doğru yönlendiğini dolaylı olarak gösteren bir bulgudur [3]. Fakat kör teknikte, iğne ucunda, ilacın epidural alana dağılımı gözlemlenemez. Tsui ve ark. [13] kaudal iğne ucunun yerinin doğrulanmasını amacıyla sinir stimulasyonu ile S2-4 sinir anal sfinkter kasılmasını değerlendirmişlerdir. Fakat, nöromusküler blokaj ile genel anestezi uygulanan pediatrik hastalarda, sfinkter kasılması olmayacağı için bu teknik uygulanamaz.

Floroskopi eşliğinde uygulanan kaudal epidural blokta opak madde enjeksiyonu ile yapılan epidurogram ile iğnenin yerinin doğruluğu teyit edilebilir [6]. Ancak, pediatrik hastalarda radyosyonun yan etkilerinde kaçınıldığı için floroskopi zorunlu kalmadıkça kullanılmaz. Buna karşın, ultrason eşliğinde kaudal blokta ortama radyasyon verilmez, hasta başı uygulaması kolaydır ve eş zamanlı görüntüleme ile ilaç enjeksiyon yeri doğrulanabilir.

Kaudal enjeksiyon sırasında ortaya çıkabilecek potansiyel komplikasyonlar cilt altı, kemik, intravenöz ve intratekal enjeksiyondur [14]. Pediatrik ve yeni doğan yaş grubunda dural kesenin (S3-S4) ve epidural venlerin (S4) daha alt seviyede olması nedeniyle kaudal epidural enjeksiyon, komplikasyonlara daha yatkın hale gelir. Wang ve ark'nın [9] 140 çocukta yaptığ randomize prospektif çalışmada; ultrason ve geleneksel yöntem ile yapılan kaudal blok karşılaştırılmış, ilk sakrokoksigeal ponksiyon başarı yüzdesi ultrason grubunda anlamlı yüksek, kan aspirasyon insidansı ve subkutan enjeksiyonu oranı ise anlamlı düşük bulunmuştur. Çalışmamızda, ilk denemede başarılı enjeksiyon oranı Grup U'da anlamlı yüksek bulundu. Her ne kadar, istatiksel olarak anlamlı olmasa da, cilt altı enjeksiyon, kan ve BOS aspirasyonu gibi komplikasyonlar, Grup U'da daha az gözlendi.

Bu çalışmayı sınırlandıran en önemli faktör, çalışmanın retrospektif dizayn edilmiş olmasıdır. Buna bağlı olarak intraoperatif vital veriler elde edilememiş ve preoperatif uygulanan kaudal bloğun intraoperatif analjezi sağlamadaki etkinliği değerlendirilememiştir. Bir diğer sınırlama ise kör ve ultrason eşliğinde uygulanan kaudal blok başarısı ve komplikasyon oranı uygulayıcının deneyimi ile ilişkilidir. Çalışmamızda tüm kaudal blok işlemleri tek ve deneyimli uygulayıcı tarafından gerçekleştirilmiştir fakat uygulayıcının deneyiminin az olmasına bağlı olarak çalışmamızdan farklı sonuçlar çıkmasına neden olabilir.

\section{Sonuç:}

Ultrason rehberliğinde kaudal blok, ilk denemede başarılı enjeksiyon oranını anlamlı şekilde arttırdı. Ayrıca, her ne kadar aralarında anlamlı bir fark olmasa da, BOS, kan aspirasyonu, cilt altı enjeksiyon gibi komplikasyonlar ve postoperatif analjezik kullanımı, ultrason grubunda daha az gözlenmiştir. $\mathrm{Bu}$ nedenle, çocuk yaş grubunda, kaudal bloğun, ultrason rehberliğinde uygulanmasını tavsiye ediyoruz.

\section{Referanslar}

1. Silvani, P, Camporesi, A, Agostino, MR, Salvo I. Caudal anesthesia in pediatric: an update. Minerva Anestesiol. 2006 Jun;72(6):453-9.

2. Jung, JY, Kim EH, Song IK, et al. The influence of age on positions of the conus medullaris, Tuffier's line, dural sac, and sacrococcygeal membrane in infants, children, adolescents, and young adults. Paediatr Anaesth. 2016 Dec;26(12):11721178 .

3. Morgan, GE, Mikail, MS, Murray, MJ. Clinical Anaesthesiology. 4th ed. Lange, 2008. pp. 273-4.

4. Mauch J, Weiss M. Pediatric caudal anesthesia: importance and aspects of safety concerns. Schmerz. 2012 Aug;26(4):44353; quiz 454.

5. R. Klocke, T. Jenkinson, D. Glew, "Sonographically guided caudal epidural steroid injections. J Ultrasound Med. 2003 Nov;22(11):1229-32.

6. Kao SC, Lin CS. Caudal Epidural Block: An Updated Review of Anatomy and Techniques. Biomed Res Int. 2017;2017:9217145.

7. Raghunathan, K1, Schwartz D, Connelly NR. Determining the accuracy of caudal needle placement in children: a comparison of the swoosh test and ultrasonography. Paediatr Anaesth. 2008 Jul;18(7):606-12.

8. Roberts, SA1, Guruswamy V, Galvez I. Caudal injectate can be reliably imaged using portable ultrasound--a preliminary study. Paediatr Anaesth. 2005 Nov;15(11):948-52.

9. Wang LZ, Hu XX, Zhang YF, Chang XY. A randomized comparison of caudal block by sacral hiatus injection under ultrasound guidance with traditional sacral canal injection in children. Paediatr Anaesth. 2013 May;23(5):395-400.

10. Ahiskalioglu, A, Yayik, AM, Ahiskalioglu, EO, et al. Ultrasound-guided versus conventional injection for caudal block in children: A prospective randomized clinical study. J Clin Anesth. 2018 Feb;44:91-96.

11. Aggarwal A, Aggarwal A, Harjeet, Sahni D. Morphometry of sacral hiatus and its clinical relevance in caudal epidural block. Surg Radiol Anat. 2009 Dec;31(10):793-800.

12. Veyckemans F, Van Obbergh LJ, Gouverneur JM. Lessons from 1100 pediatric caudal blocks in a teaching hospital. Reg Anesth. 1992 May-Jun;17(3):119-25.

13. Tsui BC1, Tarkkila P, Gupta S, Kearney R. Confirmation of caudal needle placement using nerve stimulation. Anesthesiology. 1999 Aug;91(2):374-8.

14. Zadra N, Giusti F. Caudal block in pediatrics. Minerva Anestesiol. 2001 Sep;67(9 Suppl 1):126-31.

http://edergi.cbu.edu.tr/ojs/index.php/cbusbed isimli yazarın CBU-SBED başlıklı eseri bu Creative Commons Alınt1-Gayriticari4.0 Uluslararası Lisansı ile lisanslanmıştır. 